\title{
LA ECONOMÍA Y EL DISCURSO ECONÓMICO EN LA CONSTRUCCIÓN DE LEGITIMIDAD POLÍTICA
}

\section{Un recorrido por la realidad económica y los discursos presidenciales en el contexto de salida de la crisis argentina del $2001^{1}$}

\author{
Eric Moench ${ }^{2}$ \\ Universidad de Buenos Aires, Argentina
}

\begin{abstract}
Resumen: La legitimidad política permite ejercer la autoridad en los países democráticos. Dicha legitimidad puede emanar de diversas fuentes. En este artículo abordamos las prácticas y discursos económicos del primer gobierno que tras la crisis argentina del año 2001 ha logrado recomponer cierto grado de autoridad política, luego de un par de años de carencia de ésta. Nos interesa indagar en lo económico como fundante de legitimidad, pues en países no desarrollados como lo es Argentina, las recurrentes crisis de los modelos económicos llevan a los gobiernos entrantes a basar su legitimidad en el antagonismo frente al anterior modelo. En este sentido es que queremos explorar qué formas concretas toma este proceso, así como los límites de esta práctica.
\end{abstract}

Palabras clave: discursos, medidas económicas, legitimidad política

Abstract: Political legitimacy let exercise authority in democratic countries. Such legitimacy can stem from various sources. This paper is about economic practices and discourses of the first government after the 2001 crisis in Argentina. It has managed to rebuild some political authority, after a couple of years of lack of it. We are interested in search the economic as founding of legitimacy, like in less developed countries such as Argentina, the recurrent crises of economic models carry at the incoming government to base its legitimacy on the antagonism over the previous model. In this sense we want to explore which specifics forms take this process, and the limits of this practice.

Keywords: discourses, economic actions, political legitimacy

\section{Introducción}

En Argentina el año 2002 marca el inicio de una serie de transformaciones producto de nuevas configuraciones económicas, sociales y políticas. La crisis del año 2001 y sus múltiples dimensiones -sociales, económicas, políticas, culturales- crea condiciones para una sociedad al borde de la fragmentación, que descree de sus instituciones y de sus representantes: ¿cómo es posible

\footnotetext{
1 El presente artículo es una reformulación de un trabajo más extenso presentado a la cátedra "El desarrollo como práctica y como ideología", a cargo de Ricardo Aronskind (UBA - Facultad de Cs Sociales).

2 El autor actualmente está cursando la Maestría en Cs Sociales del Trabajo (UBA-CEILPIETTE) y forma parte del Programa del Área de Investigación en Trabajo y Empleo (PAITE) a cargo de la Dra. Marta Panaia, con sede en el Instituto Gino Germani, en Bs As. E-mail: moench.eric@gmail.com
} 
lograr legitimidad política para un gobierno en el marco de protestas diarias -de todos los segmentos sociales-, conflictos laborales, alta desocupación, descreimiento de los funcionarios públicos, e insatisfacción de las instituciones públicas y privadas? El "que se vayan todos" 3 resume el cuadro de situación.

El modelo económico de los '90 -la convertibilidad- se desintegra al declararse la devaluación de la moneda nacional. En este contexto se debe encarar una doble tarea: hacer nacer un nuevo modelo económico y fundar legitimidad política que pueda hacerlo sustentable. En este cruce hace eje el presente artículo.

Este contexto político-económico muestra la necesidad imperiosa de reconstruir formas de autoridad que regeneren la legitimidad política perdida en Argentina. Por eso lo creemos un escenario privilegiado para observar prácticas que den cuenta de esta carencia. Tomamos como referente empírico los primeros años de gobierno de Néstor Kirchner, en tanto es el primer gobierno posdevaluatorio donde se logra dar inicio a ciertos consensos que se extienden en el tiempo, en la búsqueda de fundar una nueva legitimidad política.

\section{Lo discursivo y la legitimidad}

Siendo Argentina un país fuertemente estatalista ${ }^{4}$ y presidencialista $^{5}$, las acciones del Poder Ejecutivo (PE) adquieren un rol decisivo como constructor de legitimidad política: sus propuestas -como lo son las políticas económicasdeben pasar por el tamiz de la opinión pública, en otras palabras se debe buscar que el modelo económico de un gobierno "se lo apropie" la ciudadanía 6 . La idea del presente artículo será describir, justamente, cuáles son los principales lineamientos económicos en el discurso kirchnerista, que busquen fundar legitimidad política.

Cuando me refiero a discurso lo asumo en sentido amplio: discurso como palabras, como gestos, como alianzas, como prácticas. Es por eso que necesitamos al tiempo que descubrir los discursos presidenciales, acompañarlos de un recorrido económico histórico en el cual se sustenta la enunciación discursiva. En este sentido el análisis discursivo no va a ser lineal: no puedo tomar los contenidos de los discursos y "encontrar" mecánicamente ahí los elementos "legitimatorios": los discursos siempre están atravesadas por

3 Expresión cantada en cada marcha o conflicto social y que expresa especialmente la desconfianza en la clase política

${ }^{4}$ Argentina tiene una tradición de integración social desde el Estado que viene desde la época del primer peronismo y que lo diferencia de otros países latinoamericanos: resta observar hasta que punto las reformas neoliberales de los '90 afectaron dicha tradición.

5 Históricamente en Argentina el Presidente maneja mucho más poder político que el Parlamento.

${ }^{6}$ En este sentido, en el libro "El derrumbe político, en el ocaso de la convertibilidad" se hace alusión a cómo la ciudadanía se apropió del discurso de la convertibilidad: lo que se intenta significar es que los políticos buscan que su proyecto de país tenga consenso social para hacerlo viable (Novaro -comp.- 2002) 
un contexto que les confiere todo su sentido y que se nutre de lugares, tiempos, aliados, situaciones políticas, coyunturas económicas nacionales e internacionales, hechos sociales diversos, etc. que condicionan y le dan dinámica a un discurso que no por cambiante debe ser necesariamente contradictorio. Desde esta perspectiva se debe realizar un análisis procesual del discurso: trazaré un recorrido de los tres años y medio de gestión del gobierno de Néstor Kirchner, los más difíciles en tanto "reconstructores" de una legitimidad política perdida y a su vez de un contexto de país con indicadores económicos y sociales críticos.

El discurso específico que aquí analizamos es el económico, pero no todo, sino aquel que busca interpelar a los demás actores y opinión pública en general y así fundar legitimidad política. Desde esta perspectiva, es que abordamos dos dimensiones del discurso económico:

el que alude al funcionamiento y lógica del modelo económico y que se sustenta en temáticas de crecimiento, consumo e inversión

- $\quad$ el que alude a la deuda externa y al sistema financiero

Comenzaremos con un breve resumen de los antecedentes ideológicoeconómicos que hegemonizaron los discursos y prácticas en Argentina en la década inmediatamente anterior a la que aquí estudiamos, pues permite comprender los "nuevos" discursos en dos vertientes: por un lado, se contextualizan los debates específicos, es decir, los debates económicos a los que se debe dar solución; pero por otro lado, y quizás es lo más importante aquí, da claves precisas para entender porqué lo dicho es fundante de legitimidad. Según Eliseo Verón y Silvia Sigal "...el análisis de los discursos sociales se interesa en las relaciones interdiscursivas (...) la unidad de análisis, por tanto, no es el sujeto hablante, el actor social, sino las distancias entre los discursos" (Verón/Sigal, 2003: 19). En este sentido también es que Aboy Carles (2001) se refiere a las fronteras de la democracia argentina, aunque lo hace indagando en la constitución discursiva de identidades políticas, elemento que no llegaremos a profundizar; nos interesa -en el contexto de crisis que aquí abordamos- observar en qué dimensiones del discurso económico se sustenta la reconstrucción de la legitimidad política, sin embargo no soslayamos el hecho que tales dimensiones podrán ser o no fundantes -como uno más de otros tantos elementos- de nuevas identidades políticas.

\section{Los Antecedentes}

\subsection{Las promesas del neoliberalismo local}

Alrededor de los años '80 comienza a observarse una reacción neoclásica en el contexto internacional frente al estado de bienestar que reinaba en los países centrales y que había sido adaptado -con sus especificidades- por los gobiernos populistas en América Latina. Dicha reacción conservadora años después se oficializaría en un documento conocido como el Consenso de Washington (CW) y que clamaba por la retirada del Estado de la economía, 
pedía por aperturas comerciales plenas entre los países, desregulaciones, privatizaciones y políticas fiscales y monetarias restrictivas. El CW iba dirigido a los gobiernos latinoamericanos para que lo apliquen en sus economías con la promesa de que el mercado era el más eficiente asignador de recursos y que inyectaría mayor competitividad a las economías latinoamericanas, lo que haría modernizar las estructuras productivas ya que ahora las empresas necesitarían adquirir tecnología para bajar sus costos y no podrían recurrir más a un Estado ineficiente, prebendario y burocrático. El aumento de la riqueza que este proceso generará -nos decían- hará que se derramen los beneficios en toda la población.

En nuestro país, la gestión de Carlos Menem (1989-1999) adoptó los consejos del CW, aunque con particularidades propias ${ }^{7}$ : el Plan de Convertibilidad disminuyó drásticamente la inflación heredada de la gestión alfonsinista y estabilizó los precios durante toda la década, pero nuestra sociedad debió pagar por este logro altísimos costos, especialmente en materia productiva y social. Veamos algunas de las "promesas" que ofrecía el neoliberalismo vernáculo a comienzos de los '90. Se partía de un diagnóstico que insistía en que la economía estaba trabada por una relación inadecuada entre el Estado y el mercado. Aquel se había involucrado con escasa eficacia en actividades productivas propias del sector privado y éste se había acomodado a la situación desarrollando una serie de comportamientos poco competitivos. Las recetas -sencillas- que se ofertaban para retomar la senda del crecimiento eran:

a) vender las empresas públicas, lo que permitiría mejorar el funcionamiento de los servicios a través de la gestión privada y aliviaría la carga de recursos que debía usar el Estado para sostener a dichas empresas deficitarias;

b) desregular la economía ${ }^{8}$, lo que introduciría competencia en diversas áreas y fomentaría un incremento de la productividad;

c) realizar una apertura económica ${ }^{9}$ plena aumentaría la disponibilidad de bienes para consumo local, obligaría a los productores locales a bajar costos y facilitaría la modernización de maquinarias;

d) fijar el tipo de cambio en forma rígida, lo que contribuiría a la estabilización de precios;

e) modificar la estructura impositiva, reduciendo impuestos a sectores empresarios y subiendo el IVA, lo que permitiría mayores inversiones privadas y mejorar la recaudación estatal;

f) descentralización del Estado hacia las provincias -especialmente en materia educativa y de salud- que permitiría mejorar las prestaciones, atendiendo las demandas específicas de cada distrito;

g) flexibilización laboral, que contribuiría a aumentar la demanda de trabajadores ya que las empresas no tendrían la obligación de agregarlos en forma permanente a la nómina salarial;

\footnotetext{
${ }^{7}$ Por ejemplo, el CW no pedía especialmente la paridad fija 1 dólar $=1$ peso que impuso el plan convertible.

${ }^{8}$ Este concepto refiere a la eliminación de organismos y reglamentaciones que orientan o protegen a determinadas actividades.

${ }^{9}$ Este concepto refiere a la eliminación de aranceles al ingreso de mercaderías importadas.
} 
h) finalmente, las reformas económicas, al sintonizar con el discurso internacional predominante, atraerían las inversiones e incrementarían el crédito internacional (Aronskind, 2001).

\subsection{Las realidades del neoliberalismo local}

De aquellas promesas poco quedó. La realidad mostró una cara muy diferente.

Las privatizaciones implicaron nuevos nichos de mercado mono u oligopólicos, con marcos regulatorios a medida de capitales concentrados que obtuvieron rentabilidades extraordinarias aseguradas por las altas tarifas y la no competencia internacional de aquellas empresas.

La desregulación de la economía fue encarada también, pero las exigencias neoliberales de desregular el mercado no fueron hechas según el modelo del CW: hubo áreas liberalizadas, otras no liberalizadas y otras re reguladas, según las conveniencias de la cúpula empresaria. En efecto, los grandes agentes económicos recurrieron a la intervención estatal cuando juzgaron que peligraban sus cuasi rentas de privilegio $^{10}$.

La apertura económica produjo constantes déficits comerciales que, sumado a un peso sobrevaluado, hizo que comprar productos e insumos importados sea mucho más barato. Este esquema articuló una estructura fabril concentrada en un minúsculo grupo de actividades que se sustentaron en la explotación de ventajas comparativas naturales (alimentos, bebidas, derivados del petróleo) obteniendo como resultado un reducido dinamismo en la nueva cúpula empresaria en cuanto a generación de cadenas de valor agregado, bajísima creación de eslabonamientos productivos e ínfima generación de puestos de trabajo: el deterioro de los precios industriales con respecto a los servicios por efecto del régimen cambiario, financiero y comercial se tradujo en menores inversiones manufactureras.

La ley de paridad fija 1 dólar = 1 peso garantizaba que toda la circulación monetaria en pesos tenga su respaldo en dólares en el Banco Central (BCRA). Esta situación generó una paradoja, clave para entender el posterior funcionamiento económico: si una economía crece aumenta la producción de bienes y servicios y entonces se debe expandir la masa de circulante para poder adquirir esas nuevas mercancías. Así, el BCRA debía emitir para garantizar que los precios no se desplomen, pero por ley se lo prohibían, ya que para emitir había que producir su contraparte en dólares. Por tanto, el crecimiento de la economía generaba intrínsecamente que hubiera que conseguir divisas para mantener el nivel de precios: como las exportaciones no eran competitivas por la paridad fija esas divisas se conseguían vía endeudamiento estatal. La lógica del modelo era perversa: a mayor actividad económica y mayor consumo se observaba mayor déficit comercial y mayor

\footnotetext{
${ }^{10}$ La definición de Nochteff indica que las cuasi rentas generan ganancias extraordinarias que, a diferencia de las tecnológicas, no se generan por innovación ni son transitorias, sino que son logradas por la preservación de privilegios otorgados y mantenidos por acción estatal.
} 
endeudamiento externo público y privado, sin que esas divisas se vuelquen al aparato productivo ni fortalezcan la capacidad exportadora del país.

Finalmente, todas las medidas tendientes a mejorar las inversiones empresarias vía baja de impuestos, flexibilización laboral, etc. no dieron los resultados esperados y la transferencia administrativa en educación y salud generó enormes brechas de calidad entre las provincias más ricas y las más pobres.

Todas estas razones hicieron inviable el modelo neoliberal, que terminó explotando en el 2001. Parecía que el caos económico-social y político-cultural que asolaba al país se "llevaría puestos" a todos los gobiernos: con la caída de De la Rúa (1999-2001) moría un modelo económico que había tenido enorme consenso entre los argentinos durante 10 años; en aquel momento muchos autores hablaban de la peor crisis recesiva de la historia Argentina: caída de más de $10 \%$ del Producto Bruto Interno (PBI), desempleo en niveles récord de alrededor del 30\%, índices de pobreza alrededor del $60 \%$, que sumados al desprestigio total de toda la clase política y del Poder Judicial configuraban una situación caótica.

\section{Prácticas y discursos sobre el funcionamiento del modelo económico}

El 25 de mayo de 2003 asumía el Presidente Kirchner con un escaso 22\% de los votos, producto de la declinación de Carlos Menem (el ganador de la primera vuelta, dos puntos arriba del santacruceño) a participar del ballotage, previendo una derrota que todas las encuestas le auguraban. En su primer discurso como presidente, Kirchner explicita algunas ideas generales de su plan económico:

"El objetivo básico de la política económica será el de asegurar un crecimiento estable, que permita una expansión de la actividad y del empleo constante, sin las muy fuertes y bruscas oscilaciones de los últimos años (...) El resultado debe ser la duplicación de la riqueza cada quince años (...) El crecimiento requerirá de una demanda creciente que aliente las inversiones, tanto para atender el mercado interno como a las exportaciones (...) Al contrario del modelo de ajuste permanente, el consumo interno estará en el centro de nuestra estrategia de expansión. Precisamente para cumplir con esta idea de consumo en permanente expansión, la capacidad de compra de nuestra población deberá crecer progresivamente por efecto de salarios, por el número de personas trabajando y por el número de horas trabajadas" (25/5/03 Kirchner habla ante la Asamblea Legislativa el día de su asunción)

Sus palabras buscan marcar rápidamente distancias con modelos económicos anteriores: el mercado interno debe estar en el centro de la escena y las tres variables enumeradas conjuntamente (salarios en alza, aumento del empleo y aumento de las horas trabajadas) definirán la masa de recursos que irán al consumo y al ahorro local. El mercado interno, fuertemente castigado en la 
época menemista, y una expansión del consumo de los sectores asalariados de la población deben ser los motores del crecimiento: aunque en ningún momento se refiere a shocks repentinos, sino a gradual recomposición del consumo vía salarios.

Tres meses más tarde y ante los reclamos de algunos sectores políticos y empresariales sobre la falta de un plan económico estratégico, Kirchner define a quienes critican la supuesta falta de plan como "raros capitalistas que se declaran como tales pero que no quieren ni creen en la competencia ni en el riesgo empresario ni en las reglas claras y transparentes ni en el consumo masivo", para luego enfatizar algunos ejes que delinearán su gestión:

"Nuestro plan es sostener una política fiscal encaminada a mantener los más altos niveles posibles de inversión pública, sin poner en riesgo el equilibrio de las cuentas públicas. El plan es mantener un superávit fiscal primario que permita cumplir los compromisos internos, la deuda social y afrontar racionalmente los pagos al exterior, la deuda externa en un marco que no ahogue el crecimiento que necesitamos (...) Queremos superar este año el 5 por ciento de crecimiento del Producto Bruto Interno, en una ejecución plurianual nos disponemos a destinar 4.500 millones a la inversión pública reactivante" (02/09/2003 Kirchner habla en el Acto Conmemorativo del Día de la Industria)

Varias claves del esquema económico puesto a rodar son expuestas claramente aquí. Se intentará mantener los índices de crecimiento del PBI que se vienen logrando desde comienzos de 2003, luego de una caída de casi el $11 \%$ de este indicador en el año 2002. Pero ¿cómo se intentará consolidar esta incipiente reactivación económica? Será central la inversión pública y el mayor consumo interno para mantener los niveles de crecimiento que se auguran, pero no a través de la emisión constante, sino aprovechando el superávit fiscal que comienza a producirse. Así, el rol del Estado cambiará decisivamente con respecto a su actuación en los años '90: de aquel que había dejado paso al mercado como articulador de la economía, se muta a un Estado que inyectará inversiones para reactivar la demanda. El "círculo virtuoso" que intentará poner en marcha el kirchnerismo se basa en mayor inversión pública que genere empleos, infraestructura y el consiguiente consumo de la población, que aliente a nuevas inversiones privadas a radicarse en el país:

"El Estado se incorporará urgentemente como sujeto económico activo, apuntando a la terminación de las obras públicas inconclusas, la generación de trabajo genuino y la fuerte inversión en nuevas obras. Tenemos que volver a planificar y ejecutar obra pública en la Argentina, para desmentir con hechos el discurso único del neoliberalismo que las estigmatizó como gasto público improductivo. No estamos inventando nada nuevo, los Estados Unidos en la década del treinta superaron la crisis económica financiera más profunda del siglo que tuvieron de esa manera. La construcción más intensiva de viviendas, las obras de infraestructura vial y ferroviaria, la mejor y moderna infraestructura hospitalaria, educativa y de seguridad, perfilarán un país productivo en materia de industria agroalimentaria, turismo, energía, minería, nuevas tecnologías, 
transportes, y generarán nuevos puestos de trabajo genuinos" (25-5-03 Kirchner habla el día de su asunción ante la Asamblea Legislativa)

La alusión a los Estados Unidos de la época de la Gran Depresión no es azarosa. Kirchner hablará varias veces a lo largo de su mandato del modelo neokeynesiano que se intenta llevar a la práctica: como ya fue escrito en la introducción, Keynes revolucionó las ideas económicas, impulsando la variable de la demanda como factor esencial para la recuperación del crecimiento luego de los años caóticos para el sistema capitalista de comienzos de los '30. No había inversión privada que se arriesgue a invertir y generar empleo y así impulsar el consumo: debía ser el Estado quien, mediante intervenciones activas en la economía a través de costosas inversiones en infraestructura genere el círculo virtuoso para sacar al país del estancamiento. La situación de Argentina a comienzos del 2002 podría compararse en cierta manera a aquella situación de los '30: retracción del consumo, falta de infraestructura y un Estado que dejó librado al mercado y a las empresas de servicios públicos privatizadas las necesarias políticas de inversión (que en muchos casos no se hicieron por la falta de controles estatales adecuados) dejaban al país en una caótica posición para enfrentar los problemas del crecimiento económico buscado. Otra vez un Estado activo y propulsor del crecimiento se hacía indispensable: en este sentido, durante la gestión actual se suceden anuncios de inversiones públicas en diversas áreas de la economía. Kirchner dispuso desde su asunción que un estrecho colaborador suyo, Julio de Vido, se haga cargo del rejerarquizado Ministerio de Planificación Federal, el cual aumenta su presupuesto enormemente año a año, con la decisión de volver a planificar y ejecutar obra pública en Argentina. Esto -según el presidente- ayudará a "....incrementar la velocidad de la recuperación económica" (1-3-04). Se busca construir y refaccionar hospitales, escuelas, cárceles, caminos. Se impulsan planes de vivienda con el Programa Federal de Reactivación de Obras Fonavi. Se inician procesos licitatorios para el Plan Federal de Transporte de Energía para interconectar las distintas regiones del país con la Patagonia. Se reinician obras paralizadas y se licitan e inician obras de la red vial nacional. Se proyectan inversiones para el Plan Federal de Control de Inundaciones. Se comienza a recuperar servicios de pasajeros y talleres ferroviarios ${ }^{11}$.

El 18 de febrero del 2004 se hace la presentación del Plan Anual Nacional de Inversiones Ferroviarias donde Kirchner señala que:

“...durante mucho tiempo, y especialmente durante la última década, Argentina dejó de hacer inversiones en infraestructura básica, fundamental, ya sea en el marco de los transportes, de las rutas, del ferrocarril (...) ahora cuando volvemos a generar reactivación, cuando volvemos a generar crecimiento económico en la Argentina, nos encontramos con graves problemas de infraestructura en todas las áreas, donde muchas empresas que están creciendo fuertemente en su inversión por ahí tienen problemas de transporte de gas o distintas circunstancias en cada área que nunca más se tienen que volver a repetir en la Argentina" (18-2-04)

\footnotetext{
${ }^{11}$ Datos tomados del Ministerio de Planificación Federal, Inversión Pública y Servicios.
} 
Quizás el ejemplo del ferrocarril pueda ser ilustrativo de algunas singularidades de las nuevas políticas económicas que se diferencian de las aplicadas durante los '90: en aquellos años cerraron gran cantidad de ramales, fueron despedidos miles de trabajadores ferroviarios y como consecuencia de esto las economías regionales ${ }^{12}$ fueron enormemente deterioradas y muchos pueblos del interior del país fueron convertidos en fantasmas, aislados por el cierre del tren. La lógica de las ideas neoliberales sostenía que se debía dar prioridad a los nichos productivos más ventajosos comparativamente: en contraposición a esto, la devaluación cambiaria, sumada a las políticas de subsidios actuales, dinamizan las economías regionales que necesitan de inversión en infraestructura, tecnología y especialmente inversión en ferrocarriles para el traslado de productos para su venta interna o exportación y para la llegada de insumos provenientes de otros puntos del país. Si bien reactivar estructuras productivas y llegar con inversión pública a todos los rincones es un logro en la búsqueda de un país realmente productivo y federal, no debe perderse de vista que el gasto público que llega desde la nación a las provincias puede también ser usado como "botín" político para cooptar gobernadores e intendentes, recreando situaciones de repartos inequitativos de la riqueza nacional: valga como ejemplo paradigmático el caso de Santa Cruz -provincia en donde Kirchner desarrolló toda su carrera política- que fue altamente beneficiada por las inversiones del Estado nacional, muy por encima del resto de las provincias.

Claro que la inversión pública no sólo busca emplear gente y desarrollar infraestructura: impulsar el gasto público para realizar obras busca sostener una alianza con los capitales privados para que sean éstos los que vuelvan a invertir en el país luego de años de desinversión:

"Nosotros estamos tratando de recuperar celeridad, eficiencia, capacidad de respuesta, y poner en marcha rápidamente todo el sistema de obras públicas que es fundamental -repito- para recuperar el dinamismo de nuestra economía. Pero también es fundamental que los sectores industriales, los establecimientos fabriles, las empresas, los comercios que tienen que ver con el sector, hagan el esfuerzo de inversión en capacidad instalada. Nosotros estamos marcando una inversión que va a estar rondando los 10.000 millones de pesos, más importantes anuncios que haremos en las próximas semanas. Es decir, tienen toda una proyección para preveer la inversión" (14-7-04 Kirchner habla en la Presentación del Plan Nacional de Obras Públicas)

Argentina venía de un proceso de baja utilización del tejido industrial durante los '90. En el peor momento de la crisis de 2001-'02 la inversión no alcanzaba siquiera para reponer el capital que se amortiza anualmente. Así, la crisis provocó una enorme contracción en el stock de capital industrial. Por su parte, el sector servicios había expandido su participación en el PBI durante los '90, pero una estructura muy concentrada de las ganancias y un tipo de cambio que ahora no favorece tanto a las empresas del sector hacen pronosticar una caída de la tasa de inversión. Finalmente, el agro -especialmente en la región pampeana con los grandes productores rurales- había obtenido beneficios a

\footnotetext{
${ }^{12}$ Este concepto refiere especialmente a pequeñas y medianas empresas del interior del país dedicadas a producir y exportar materias primas y productos agroindustriales.
} 
través de la exportación de productos primarios y agroindustriales, impulsados por innovaciones tecnológicas.

Pero la ventaja potencial -si se la puede llamar así- que tenía el país es la capacidad instalada que estaba en desuso, es decir, luego de la crisis había margen para aumentar la producción sin tener que invertir en principio demasiado en equipamiento.

Desde el comienzo de la gestión se busca marcar que el proyecto oficial hace eje en la producción y en la productividad a partir de crear condiciones de mayor consumo interno:

"Sin el consumo creciente la recuperación se queda sin locomotora y el crecimiento sostenido no define su sendero. Sin consumo no hay ni mercado ni hay solución. Sin mercado interno creciente y demandante, las inversiones se ubican en sectores especulativos, inmobiliarios, dirigidos a una pequeña porción de la población o donde el Estado garantiza con su regulación tasas de enorme rentabilidad. Para que la inversión se dirija a las actividades productivas que eleven la productividad de la economía y expandan la frontera del desarrollo deben combinarse un mercado interno creciente y las oportunidades de exportación de mercaderías al mundo" (1-3-04 Kirchner habla en la Inauguración de Sesiones del Congreso)

Desde el Estado se busca seducir a los capitales privados, atraídos por una mayor demanda interna, para que realicen mayores inversiones y que suban su productividad. Pero la estrategia no es del todo coherente: por momentos se insiste en que debemos crecer "basados en la productividad y la competitividad de nuestras sociedades y no en la competencia hacia abajo de los salarios" (16-12-03). En otros momentos se busca seducir a los inversionistas extranjeros a partir de la baja de costos salariales que generó la devaluación del país: "En materia de industria y servicio, la globalización exige de localizar o complementar producciones para mantener competitividad. Los costos argentinos son ahora altamente competitivos. Contamos con recursos humanos ubicados ampliamente por encima del promedio del mundo en desarrollo..." (20-1-05).

Lo concreto es que el aumento de los niveles de consumo interno, sumado a la devaluación que impulsa una incipiente sustitución de importaciones de algunos bienes y servicios, hizo que los sectores productivos nacionales mejoraran su producción. La productividad de las empresas aumentó: sin embargo, este aumento se explica en gran parte por la mayor utilización de la capacidad instalada de dichas empresas, es decir, se puso en marcha la maquinaria productiva inmovilizada, pero se realizaron pocas inversiones que amplíen la capacidad productiva, es decir, la reactivación no posibilitó aún un proceso sostenido de inversión en nuevos equipamientos tecnológicos. Desde el gobierno se empieza a orientar el discurso, sobre todo desde el 2005, hacia la superación de los niveles de inversiones: la capacidad instalada comienza a utilizarse al máximo de su potencial y sin compras de equipos productivos modernos la producción se encontrará con un tope que paralizaría la actividad: 
"En el agro, la industria, la construcción y los servicios, la inversión debe subir por lo menos otros dos puntos y medio del Producto Bruto Interno. Desde el Estado se favorecerá la inversión y reinversión productiva" (1-3-05 Kirchner habla en la Inauguración de Sesiones del Congreso)

Lo que se observa es que todos los rubros de la industria -excepto el área de tabaco- superan los magros resultados de los peores años de la crisis (2001'02). En muchos de estos rubros, ya en el 2005, la industria comienza a superar la producción de algunos de los mejores años de la convertibilidad ('96-'97-'98): entre los sectores que mejoraron su producción con respecto a aquellos años se destacan la producción de papel y cartón, textiles, sustancias y productos químicos y las industrias metálicas básicas. La nueva macroeconomía favoreció especialmente las actividades intensivas en empleo, pero éstas no son de las que más valor agregan: muchas Pymes trabajointensivas volvieron a ser rentables.

Uno de los sectores que más ha crecido en esos años es el automotriz. Pero se partía de niveles de actividad muy deprimidos en el área. Varias veces Kirchner irá a las plantas automotrices a elogiar el aumento de inversiones o la inauguración de plantas industriales: "Es una inversión muy importante, 50 millones de dólares que se ponen en marcha, creo que la Argentina está viviendo un proceso de reindustrialización muy importante, con inversiones realmente vitales" decía el 21 de abril de 2005 en la Inauguración de una Nueva Sede de DaimlerChrysler. Unos meses más tarde sostenía en una visita a la planta de Honda Motor: "A veces parece un sueño poder venir a inaugurar una planta de estas calidades, que genera inversión en la Argentina, que genera motopartes argentinas; que consolida el perfil industrial que los argentinos queremos darle a este país".

En este proceso de reactivación ha crecido la industria, pero especialmente ha avanzado la construcción: creció a tasas inéditas desde el 2003 en adelante, superando a los índices de los '90. El enorme aumento de la construcción es originado especialmente a partir de la reducción de costos de mano de obra y del aumento del consumo interno y poder de compra de las clases media-alta y alta.

Uno de los principales beneficiados por el nuevo tipo de cambio es el agro. Gracias a la devaluación y a los altos precios internacionales las economías regionales rápidamente se dinamizaron y los grandes productores pampeanos siguieron alcanzando niveles récord de cosechas, ayudados por la tecnología en maquinaría que habían incorporado especialmente en la década pasada: la soja se convirtió en la principal exportación del campo nacional. En el agro la estrategia del gobierno se orienta principalmente a seguir mejorando la productividad del sector a través de mayores inversiones en biotecnología y mejoras en los métodos de producción. En este sentido, las relaciones con China buscaban orientarse hacia los aspectos de inversión científica y tecnológica que puede aplicar aquel país, utilizando nuestros recursos humanos calificados en el área: 
"Nuestros productores y empresarios agropecuarios tienen una aquilatada experiencia en materia de innovación tecnológica, ello nos ha permitido acortar los plazos de producción, mejorar la eficiencia de las cosechas y duplicar la producción cada diez años. Estos plazos podrían incluso ser menores con mayores inversiones desde el desarrollo de la biotecnología, que facilite el movimiento transfronterizo de organismos genéticamente modificados. Debemos trabajar en el desarrollo de germoplasma de trigo y soja, encarar estudios conjuntos sobre genómica y bioinformática, realizar y transferir técnicas para pequeños productores en siembra directa, genética animal, manejo de pasturas, métodos de producción y coordinación de aspectos sanitarios" (28-6-04 Kirchner habla en el Seminario Argentina - China: Socios para el Crecimiento)

En definitiva, el plan propuesto para volver a la senda del crecimiento es una alianza entre Estado y mercado: aquel generará condiciones de infraestructura y niveles de consumo que vuelvan rentables las iniciativas privadas en industrias, servicios y en el campo. Es decir que la opción propuesta no es suplantar al mercado sino apoyarlo para que las empresas y productores puedan nuevamente invertir en el país: en este sentido se siguen algunos lineamientos que el Banco Mundial (BM) había propuesto desde mediados de los '90 para aliviar los escasos resultados en materia de desarrollo que habían traído las ideas neoliberales que ellos mismos impulsaron años atrás. En efecto, una de las nuevas ideas del BM es que no todo debe hacerlo el mercado, y el Estado debe estar ahí donde aquel no llega: debe invertir en educación, salud pública, medio ambiente e infraestructura (Bustelo, 1998: 177). Así, las empresas bajan sus costos: tienen un inversor público que les ahorra la tarea de generar recursos humanos y materiales que luego emplearán para su beneficio privado.

Pero también en las nuevas recetas planteadas por el BM se alude a que el Estado debería abstenerse de llevar a cabo actividades de producción y de distribución directas (Bustelo, 1998: 174). Aquí Kirchner se aparta del ideario del BM luego de transcurrido más de un año de gestión: empieza a realizar críticas a ciertos servicios públicos que administran empresas privadas extranjeras y finalmente rescindirá contratos de servicios que pasan nuevamente -luego de más de diez años- a la órbita estatal. Las empresas privadas de servicios son claramente diferenciadas por el gobierno: están aquellas que realizan inversiones y aquellas que no, siendo estas últimas incumplidoras de contratos. Evidentemente, el tipo de cambio nuevo ( 3 pesos = 1 dólar) no las beneficia excesivamente a las concesionarias como durante los '90 y algunas deciden no invertir más en el país.

Durante la presentación de planes de inversión del grupo español Telefónica, Kirchner elogia calurosamente las nuevas inversiones planeadas en el área de telecomunicaciones que se dice rondarán los 2 mil millones de dólares y aclara que "en ningún momento acá $-\mathrm{y}$ deben saberlo todos los argentinos porque esto es importante- he recibido ningún condicionamiento de aumento de tarifas o algún otro tipo de especulación que a veces se hace, para hacer inversiones en la Argentina" (05/11/2003) y así marca cuáles serán las empresas de 
servicios "premiadas" por su gestión. Pero la presión para aumentar tarifas de servicios venía desde varios lugares, especialmente del Fondo Monetario Internacional (FMI): la excusa esgrimida era que las inversiones atrasadas eran indispensables para el buen funcionamiento y la modernización del servicio, pero que no había rentabilidad con las actuales tarifas congeladas. La disputa entre gobierno y privatizadas continuará y la escalada de enfrentamientos irá en ascenso; las empresas "castigadas" por el gobierno no serían simplemente "retadas" por el presidente, sino que muchas se terminarán yendo del país:

"La verdad es una sola: el Estado Nacional no maneja ni la producción ni maneja la distribución del gas en la Argentina, está en manos de privadas y evidentemente si creyeron que la Argentina iba a crecer menos o si generaron o trataron de exportar por allí todo lo que no podían exportar, la verdad que no es culpa nuestra (...) Nosotros estamos dispuestos a participar y ahí está la decisión de volver a tener una Empresa Nacional de Energía (...) voy a tomar todas las medidas que sean necesarias para que la Argentina tenga el abastecimiento de gas, solucione y pueda superar este 2004, tenga una estabilidad en 2005 y un horizonte estratégico definitivo en la ecuación energética en el 2006.(...) Les pido a las empresas del sector también que tengan una relación directa entre ellas mismas para saber qué es lo que invirtió cada una. Hay empresas que han invertido cerca de un 18 por ciento y otras que han invertido solamente un 2 por ciento. Ustedes saben quién de cada uno hizo esa inversión y nosotros también lo sabemos" (11-5-04 Kirchner habla en la Presentación del Plan Energético Nacional)

En este marco de ásperas negociaciones el gobierno decide rescindir los contratos con Correo Argentino y hacerse cargo de la concesión, crear en 2004 Energía Argentina Sociedad Argentina (ENARSA) para participar en el mercado de hidrocarburos y energía ${ }^{13}$, a comienzos del 2006 se crea Aguas y Saneamiento Argentino Sociedad Anónima $(A y S A)^{14}$, se quita también la concesión a la empresa francesa Thales, encargada del espacio argentino aéreo. Luego de estos realineamientos, desde el gobierno se anuncian inversiones en distintas zonas del país tanto para construir generadores de energía como para llevar cloacas y agua potable a mayor población.

Más allá de las peleas y negociaciones desatadas, se hace claro que el gobierno no desprecia las inversiones extranjeras, muy por el contrario intenta seducirlas para que se radiquen en el país: siguiendo esta premisa el 16 de noviembre del 2004 se firman en Buenos Aires acuerdos con el presidente chino Hu Jintao que los medios de comunicación titulan en tapa "Ambos países estudiarán la posibilidad de que la nación asiática desarrolle proyectos por unos US\$19.000 millones en diez años" (Diario La Nación, 17-11-2004). Además, desde el 2004 se vienen intensificando los acuerdos con Venezuela, especialmente en lo que hace a inversiones energéticas de Petróleo de Venezuela Sociedad Anónima (PdVSA). Más adelante, el 22 de junio de 2006

\footnotetext{
${ }^{13}$ Enarsa será una empresa mixta donde el Estado nacional participará mayoritariamente con el $53 \%$ de las acciones, el $12 \%$ será de las provincias y el $35 \%$ restante estará destinado a inversores privados.

${ }^{14}$ Aquí se le quita la concesión a Aguas Argentinas, empresa mayoritariamente de capitales franceses.
} 
durante una visita al parlamento español Kirchner insistirá "Si Repsol invierte fuerte en la Argentina la producción de gas y de petróleo puede crecer muchísimo". La situación energética es un ejemplo que muestra claramente como los precios relativos se modificaron para las empresas de servicios extranjeras: actualmente el Estado se debe hacer cargo de la gran demanda de energía que, sumado a las desinversiones crónicas del sector, están provocando "cuellos de botella" en varias industrias.

\section{El discurso sobre la deuda externa y el sistema financiero}

Consolidar el PBI es clave para Kirchner en su objetivo de mejorar la recaudación para lograr un superávit fiscal primario ${ }^{15}$ que permita pagar lo adeudado a los organismos de crédito internacionales y demás acreedores externos e internos. Muchas voces dentro del Partido Justicialista (PJ) habían aclamado la declaración del default argentino (cesación de pagos) durante la breve presidencia de Adolfo Rodríguez Saá y muchas otras voces desde la izquierda política pedían la suspensión de una deuda considerada ilegítima: sin embargo, desde el comienzo de su gestión Kirchner declara que "...sabemos que la deuda es un problema central. No se trata de no cumplir, de no pagar. No somos el proyecto del default" (25-5-03). Seguidamente en los discursos se plantea la necesidad de pagar según la capacidad de crecimiento del país, esto es, a partir de porcentajes que variarán según la evolución del PBI y negociando tres objetivos básicos: reducción de los montos de la deuda, reducción de las tasas de interés y ampliación de los plazos de vencimiento de los bonos en default.

El primer acuerdo con el FMI fue logrado en septiembre del 2003 y el organismo de crédito se comprometía a refinanciar todos los vencimientos de capital que la Argentina adeudaba durante los siguientes tres años, que sumaban aproximadamente $\$ 12.000$ millones, mientras que Argentina debería abonar los \$2.000 millones por año -durante tres años- de vencimiento de intereses de deuda. Además, nuestro país se comprometía a lograr un superávit fiscal primario del 3\% para el año 2004 y a determinar en 2005 y 2006, superávit que aseguraría el pago de deuda. Desde el comienzo de su gestión el gobierno de Kirchner tuvo con el FMI una relación controvertida: si por un lado se negociaba para pagar la deuda contraída, por el otro se hacían constantes críticas y se pedían cambios en el organismo que incluyan:

"...el cambio de sus paradigmas, de modo que el éxito o el fracaso de las políticas económicas se mida en términos de éxito o fracaso en la lucha por su crecimiento, la equidad distributiva, la lucha contra la pobreza y el mantenimiento de niveles adecuados de empleo. Este nuevo milenio debe desterrar los modelos de ajuste que basan la prosperidad de unos en la pobreza de otros" (25-9-2003 Kirchner habla en la 58 Asamblea General de las Naciones Unidas)

\footnotetext{
${ }^{15}$ Este concepto mide la diferencia entre ingresos y gastos públicos, sin descontar los pagos de la deuda externa.
} 
Un año después, en el mismo escenario, Kirchner volvía a "hacer equilibrio": si por un lado sostenía que los superávit fiscales eran necesarios para estabilizar la economía y respetar las obligaciones con la comunidad financiera internacional, por otro lado argumentaba que no se debía lograr dicho superávit podando partidas presupuestarias destinadas a la inversión pública.

Lo cierto es que el acuerdo con el FMI sirvió de puente para llegar a una reestructuración de la deuda en default (que era de 110.000 millones de dólares) y para reducir el riesgo asociado a la deuda ${ }^{16}$. El 1 de marzo del 2005 en la Inauguración de Sesiones del Congreso el presidente decía efusivamente:

"Argentina ha podido concretar exitosamente el más gigantesco canje de deuda en cesación de pagos de la historia mundial y lo ha hecho en el marco de la concreción de la quita más grande de la historia".

Dos días después se presentaban los resultados finales: un $76 \%$ de los acreedores canjearon sus acciones por nuevos bonos y la deuda externa global disminuía más de 65 millones de dólares. El diario La Nación publicaba "La mayoría de los asistentes manifestó su aprobación respecto de los discursos oficiales, aunque por lo bajo cuestionó las críticas presidenciales hacia los economistas Daniel Artana, Pablo Guidotti, Manuel Solanet, Miguel Kiguel, Carlos Melconián y José Luis Espert, entre otros". La cita sirve para ilustrar los vaivenes de la negociación: cuando se había presentado en Dubai la estrategia oficial de quita de deuda, algunos sectores, economistas y políticos especialmente los ligados a organismos económicos neoliberales, como FIEL, CEMA, Fundación Mediterránea, etc.- habían criticado la posición argentina aduciendo que una quita tan amplia como la propuesta reduciría la credibilidad del país ante el mundo. Luego de canjeada la deuda aquellos sectores se defenderán diciendo que la quita no había sido tan grande como la propuesta originalmente en Dubai. En definitiva, hubo pocas voces de desaprobación con las negociaciones concluidas y sólo algunos sectores -el diario La Nación, las instituciones citadas- pedían que se resuelva rápidamente el tema de los acreedores que no entraron al canje.

Decía antes que se transitaba un sendero lleno de ambigüedades en torno a la relación con el FMI, situación que también se observa con el BM: se negocia al mismo tiempo que se pide un rediseño del organismo para que cumpla un rol contracíclico en la región (que ayude a salir de depresiones económicas). Kirchner les alerta "No parece mal que trabajen activamente en cooperación con el sector financiero privado, pero deben cuidadosamente evitar quedar prisioneros o ser los gestores de los intereses particulares" (22-11-05). La política de confrontación y negociación se diluirá pronto, al menos con el FMI: luego que Brasil anunciara sorpresivamente el pago total de su deuda con aquel organismo, Argentina decide imitarlo. Se pagará antes del final del 2005 los 9.810 millones de dólares de capital que se le adeuda: una vertiginosa recomposición de las reservas desde el piso que hubo en el 2002 haría posible

${ }^{16}$ Los indicadores que se usan para medir el riesgo asociado a la deuda para un país son básicamente dos: el porcentaje de la deuda externa en relación al PBI y la relación de la deuda total con el monto de las exportaciones. 
la operación ${ }^{17}$. En un discurso donde se hacen presentes empresarios, políticos -oficialistas y opositores- y sindicalistas, entre otros, la escalada de críticas al organismo internacional sube de tono y la ambigüedad anterior da paso a duros cuestionamientos; el pago se asume desde el gobierno como mayor autonomía para diseñar políticas económicas no condicionadas por la ortodoxia del FMl:

"En los últimos 30 años hemos visto avanzar la continua dependencia de programas que Argentina acordó con el Fondo Monetario Internacional. Formamos parte de la triste realidad de integrar el grupo de países en los que esa institución ha aplicado y monitoreado mucho de sus 150 planes de ajuste. El resultado ha sido exclusión, pobreza, indigencia, la destrucción del aparato productivo. A la sombra de esos programas hemos visto concentración de ingreso en unos pocos y hemos chocado contra la imposibilidad de combinar crecimiento macroeconómico con desarrollo social y pleno empleo" (15-122005)

Sin embargo, que se hayan pagado sumas importantes de deuda no significa que este gobierno busque una autarquía plena en materia financiera: muy por el contrario, se siguen solicitando créditos a otros organismos multilaterales como el BM y el Banco Interamericano de Desarrollo (BID). Nuevamente aquí se inscribe una lógica más pragmática que principista; no es que no necesitemos crédito externo, la diferencia es quiénes nos lo dan -qué condiciones nos imponen- $y$ adónde se orienta:

"...durante muchos años la Argentina pedía créditos al Banco Mundial para pagar deudas, y ahora los créditos del Banco Mundial son destinados a las obras de infraestructura, obras de reconversión educativa. Es decir, no queremos más ese tipo de créditos para pagar deudas porque es absolutamente negativo ese tipo de procedimiento" (22-6-06 Kirchner habla ante el Parlamento español)

Además de seguir recibiendo créditos de los organismos internacionales -tanto el BM como el BID continuando financiando al país actualmente- la gestión actual busca intensificar la exploración de nuevos mercados de capital no tradicionales: desde el comienzo la asociación de Argentina con Venezuela incluyó la compra de bonos de la deuda argentina que el presidente Hugo Chávez llevó adelante en reiteradas ocasiones. Además, una de las formas de promover el crédito y la baja de la tasa de interés financiera está siendo negociada en los últimos meses: se intenta conseguir nuevas fuentes de financiamiento creando nuevos bancos para el desarrollo regional:

"Nosotros estamos aspirando a crear un Mercado del Sur, queremos y estamos trabajando en forma paulatina para generar en ese Mercado del Sur Bonos del Sur que, en una primera etapa, serían llevados adelante por la República Bolivariana de Venezuela y la Argentina (...) Creemos que puede ser un esquema de financiamiento muy importante y que puede generar también una cantidad y una calidad de operaciones que va a bajar absolutamente por ahí

${ }^{17}$ El 31 de diciembre del 2002 las reservas públicas sumaban 10.476 millones de dólares. El día del pago al FMI -tres años después- las reservas ascendían a 28.077 millones de dólares (Fuente: INDEC). 
los costos que tenemos hoy cada vez que tenemos que salir al mercado" (10-706 Kirchner habla en el 152 Aniversario de Creación de la Bolsa de Valores de Buenos Aires)

Tenemos entonces una estrategia que implica no tomar deuda para cubrir deuda -como ocurría durante la década del '90-, no tomar créditos que impliquen negociar ajustes internos, y usar el dinero para la inversión pública, tanto física como social. Pero ¿qué sucede con el sistema financiero local? Lejos de considerar que en un esquema que se pretende productivo lo financiero debe hacerse a un lado, Kirchner convoca al mercado de capitales privados locales a prestar dinero para el crecimiento del país:

"Se escandalizan cuando pedimos a los bancos que otorguen préstamos a los sectores productivos (...) Bien se ha dicho aquí que, contrariamente a lo esperado, las entidades bancarias privadas acumulan una liquidez inusual que no se encargan del volcar al crédito. Una política de restricción crediticia no guarda ninguna lógica en un país que demanda del auxilio financiero interno para favorecer su despegue económico definitivo. La acción decidida de los bancos públicos -Nación, Ciudad y de la Provincia de Buenos Aires- ha permitido volcar recursos para facilitar la producción y el consumo. Aún así, nadie duda de la insuficiencia de ese esfuerzo. Es hora de que una vez y para siempre el sistema financiero argentino deje de mirarse a sí mismo y se asocie al esfuerzo nacional" (02/09/2003 Kirchner habla en el Acto Conmemorativo del Día de la Industria)

Como se observa hay una embestida desde el comienzo de la gestión para que la actividad financiera privada oriente sus créditos hacia la producción, siguiendo una supuesta acción del Estado a favor de sectores productivos: es central para el gobierno no ahogar el incipiente crecimiento y que el sector público no desplace al sector privado de la financiación. Es decir, no se busca un Estado que tome crédito constantemente, sino el rol que debe ocupar éste es el de promover liquidez crediticia que se vuelque al sector privado productivo: contrariamente al Estado de los '90, ahora se necesita un sector público que desde sus bancos otorgue préstamos dinámicamente a empresas privadas para que éstas produzcan bienes y servicios así como para que incrementen la capacidad de producción instalada de sus plantas para favorecer el crecimiento.

En suma, este breve recorrido muestra notables diferencias entre el funcionamiento de las políticas financieras vigentes y las implementadas durante los '90. En el esquema actual observamos una lógica de desendeudamiento - canje de deuda con quita, pago total al FMI, a lo que se podría sumar la proyectada cancelación de deuda con el Club de París-, que sin embargo no genera una huida del crédito internacional: lo que se modifica es la orientación que se le da a los créditos tanto externos como internos y el rol que juega el Estado en el mercado de capitales, así como se observa también la presencia de nuevos prestamistas no tradicionales. El rol que cumple el Estado se redefine a partir de las nuevas condiciones: no se necesita ni se busca que el sector público salga constantemente a tomar crédito para mantener el funcionamiento de la economía, sino que se requiere de un Estado 
con solvencia fiscal que evite el endeudamiento que hubo durante los ' 90 , de modo que se liberen fondos para el sector privado.

\section{Comentarios finales}

La evidencia empírica vertida en este artículo permite dar cuenta de una de las formas posibles de fundar legitimidad política. Lo económico, en tanto prácticas concretas y discursos que se enuncian, es una dimensión desde la que se puede fundar legitimidades políticas.

En concreto, en la realidad argentina del año 2003, era imperiosa lograr dicha legitimidad pues el presidente Kirchner asumía con menos del $25 \%$ de los votos. Pudo lograr cierta legitimidad apelando a lo económico -para otra discusión dejamos el tema de las contradicciones entre las acciones concretas y lo discursivo-. En este sentido las reiteradas referencias a la década pasada sirven para diferenciar el funcionamiento entre el esquema económico actual y el de los '90. Se busca hacer emerger un nuevo modelo económico -como producto de las prácticas concretas y de los discursos presidenciales- como "lo opuesto" al anterior modelo. Asociando este anterior modelo al "ajuste permanente", al estado "desinversor", al desempleo -entre muchas otras negatividades-, el nuevo modelo toma por oposición características diferenciales y positivas, y en este antagonismo ancla su legitimidad política.

El éxito -y al mismo tiempo el límite- para sostener esta legitimidad estará dado por lograr que esta articulación entre las acciones económicas y lo discursivo haga sentido en la ciudadanía, es decir, que en ésta se origine un consenso sobre el modelo económico implementado; dicho consenso se articula tanto a partir de las acciones como de los discursos.

\section{Bibliografía}

\section{Libros:}

a) (2001) ABOY CARLES, Gerardo, Las dos fronteras de la democracia argentina, Ed. Homo Sapiens, Rosario

b) (2001) ARONSKIND, Ricardo, ¿Más cerca o más lejos del desarrollo? Transformaciones económicas en los '90, Ed. Libros del Rojas (UBA), Buenos Aires

c) (1998) BUSTELO, Pablo, Teorías contemporáneas del desarrollo económico, Ed. Síntesis, Madrid

d) (1984) HIRSCHMAN, Albert, De la economía a la política y más allá, Ed. Fondo de Cultura Económica, México

e) (2002) NOVARO, Marcos (comp.), El derrumbe político en el ocaso de la convertibilidad, Grupo Editorial Norma, Buenos Aires 
f) (1987) VERON, Eliseo, "La palabra adversativa" en Verón, Eliseo et al.: El discurso político. Lenguajes y acontecimientos, Ed. Hachette, Buenos Aires g) (2003) VERON, Eliseo y SIGAL, Silvia, Perón o muerte. Los fundamentos discursivos

del fenómeno peronista, Ed. Eudeba, Buenos Aires

\section{Fuentes:}

Página web de Presidencia de la Nación. Todos los discursos presidenciales están disponibles en sitio web: www.presidencia.gov.ar 